\title{
The Impact of Admission Serum Creatinine Derived Estimated Glomerular Filtration Rate on Major Adverse Cardiac Events in ST-Segment Elevation Myocardial Infarction Patients Undergoing Primary Percutaneous Coronary Intervention
}

\author{
Mahmut Uluganyan ${ }^{\mathrm{a}, \mathrm{f}}$, Gurkan Karaca ${ }^{\mathrm{b}}$, Turker Kemal Ulutas ${ }^{\mathrm{c}}$, Ahmet Ekmekci $^{\mathrm{d}}$, Eyup Tusun ${ }^{\mathrm{d}}$, \\ Ahmet Murat ${ }^{\mathrm{d}}$, Bayram Koroglu ${ }^{\mathrm{d}}$, Huseyin Uyarele ${ }^{\mathrm{e}}$, Nijad Bakhshaliyev ${ }^{\mathrm{d}}$, Mehmet Eren ${ }^{\mathrm{d}}$
}

\begin{abstract}
Background: The impact of Cockroft-Gault (C-G) derived estimated glomerular filtration rate (eGFR) on mortality and major adverse cardiac events (MACEs) in patients with ST-segment elevation myocardial infarction (STEMI) undergoing primary percutaneous coronary intervention (PCI) was assessed.
\end{abstract}

Methods: A total of 884 patients were classified into four categories according to admission creatine derived eGFR: $<60,60-<90,90-<$ 120 , and $\geq 120 \mathrm{~mL} / \mathrm{min} / 1.73 \mathrm{~m}^{2}$.

Results: In-hospital and long-term MACEs were significantly higher in eGFR $<60 \mathrm{~mL} / \mathrm{min} / 1.73 \mathrm{~m}^{2}$ subgroup $(\mathrm{P}<0.001$ and $\mathrm{P}=0.028)$. Multivariate analysis demonstrated 7.78-fold (95\% CI: 0.91 - 66.8) higher mortality risk in eGFR $<60 \mathrm{~mL} / \mathrm{min} / 1.73 \mathrm{~m}^{2}$ subgroup.

Conclusion: As an easily applicable bedside method, C-G derived eGFR could be important for prediction of in-hospital and long-term mortality and MACE in STEMI patients undergoing primary PCI.

Keywords: Estimated glomerular filtration rate; Cockcroft-Gault; Mortality; ST-segment elevation myocardial infarction; Major adverse cardiac events

Manuscript accepted for publication February 10, 2016

${ }^{a}$ Clinic of Cardiology, Kadirli Government Hospital, Osmaniye, Turkey ${ }^{\mathrm{b}}$ Clinic of Cardiology, Osmancik Government Hospital, Corum, Turkey ${ }^{c}$ Clinic of Biochemistry, Kadirli Government Hospital, Osmaniye, Turkey ${ }^{\mathrm{d}}$ Clinic of Cardiology, Dr Siyami Ersek Thoracic and Cardiovascular Surgery Center Training and Research Hospital, Istanbul, Turkey

eDepartment of Cardiology, Bezmialem Vakif University Medical Hospital, Istanbul, Turkey

${ }^{f}$ Corresponding Author: Mahmut Uluganyan, Sehit Orhan Gok Mah, TOKI Evleri DG1-A Kat 4 Daire 8 Kadirli, Osmaniye, Turkey.

Email: uluganyan@yahoo.com

doi: http://dx.doi.org/10.14740/jocmr2482w

\section{Introduction}

Chronic kidney disease (CKD) is a significant and independent cause of cardiovascular adverse events and mortality in general population and patients with cardiovascular diseases [14]. Additionally, in many studies, it has shown that any degree of renal impairment assessed by estimated glomerular filtration rate (eGFR) is related to increased adverse cardiovascular outcomes and predicts in-hospital, short- and long-term mortality in acute coronary syndrome (ACS) and general population [5-8]. Decreased renal function assessed by eGFR predicts prognosis in both genders in ST-segment elevation myocardial infarction (STEMI) [9]. In STEMI patients undergoing primary percutaneous coronary intervention (PCI), poor myocardial perfusion and increased no-reflow phenomenon were detected in patients with decreased eGFR $[10,11]$. Two recent studies have shown relation between decreased eGFR and increased burden of atherosclerosis and decreased left ventricular ejection fraction (EF) in various forms of ACSs [12, 13]. Renal dysfunction is associated with female gender, older age, hypertension (HT), and diabetes mellitus (DM) [7]. These factors are linked with worse clinical outcomes.

In the present study, we investigated the relation between admission serum creatine $(\mathrm{Cr})$ derived eGFR and in-hospital and long-term adverse cardiac events in STEMI patients undergoing primary PCI.

\section{Materials and Methods}

This retrospective observational single-centered study was conducted between May 2009 and 2011. Patients presenting with STEMI undergoing primary PCI were enrolled. Patients with unstable angina, non-STEMI and STEMI that did not undergo primary PCI were excluded. The European Society Cardiology/American College of Cardiology Foundation/ American Heart Association (ESC/ACCF/AHA) committee advisement of ECG criteria was used for diagnosis of STEMI $[14,15]$. These were definitive new bundle branch block or $>$ $0.1 \mathrm{mV}$ new ST elevation in two contiguous leads. The proce- 
Table 1. Demographics of All Patients by Estimated Glomerular Filtration Rate

\begin{tabular}{|c|c|c|c|c|c|}
\hline \multirow{2}{*}{ Demographics } & \multicolumn{4}{|c|}{ Estimated glomerular filtration rates $\left(\mathrm{mL} / \mathrm{min} / 1.73 \mathrm{~m}^{2}\right)$} & \multirow{2}{*}{$\mathbf{P}$} \\
\hline & $<60$ & $\geq 60-<90$ & $\geq 90-120$ & $\geq 120$ & \\
\hline Patient no., n (\%) & $72(8.1)$ & $390(44.1)$ & $345(39)$ & $77(8.7)$ & \\
\hline Gender (F/M), n & $20 / 52$ & $53 / 337$ & $30 / 315$ & $8 / 69$ & $<0.001$ \\
\hline Age, years & $59 \pm 8.9$ & $55.8 \pm 8.3$ & $51.1 \pm 9$ & $50.2 \pm 8.5$ & $<0.001$ \\
\hline Smoking, n (\%) & $38(52.7)$ & $238(61.1)$ & $211(60.3)$ & $57(74)$ & 0.118 \\
\hline $\mathrm{CAD}, \mathrm{n}(\%)$ & $9(12.5)$ & $80(20.5)$ & $56(16.2)$ & $14(18.2)$ & 0.262 \\
\hline Diabetes mellitus, n (\%) & $30(41)$ & $113(29)$ & $66(19)$ & $19(24.6)$ & 0.137 \\
\hline Hypertension, n (\%) & $49(68)$ & $169(43.3)$ & $103(29.8)$ & $23(29 \%)$ & 0.072 \\
\hline Follow-up, months & $18.9 \pm 16$ & $21.8 \pm 15.6$ & $22.8 \pm 14.1$ & $22.1 \pm 13$ & 0.245 \\
\hline Hospitalization, days & $9.2 \pm 5.3$ & $7.8 \pm 4.4$ & $7.1 \pm 3.8$ & $7.7 \pm 4.6$ & 0.004 \\
\hline eGFR & $50.5 \pm 9.2$ & $76.7 \pm 7.3$ & $101.3 \pm 8$ & $134 \pm 12.2$ & $<0.001$ \\
\hline Admission creatine, $\mathrm{mg} / \mathrm{dL}$ & $1.4 \pm 0.4$ & $1.03 \pm 0.1$ & $0.83 \pm 0.07$ & $0.67 \pm 0.05$ & $<0.001$ \\
\hline CK-MB, U/L & $310 \pm 215$ & $216 \pm 182$ & $231 \pm 177$ & $225 \pm 186$ & $<0.001$ \\
\hline Leucocyte, $10^{3} / \mu \mathrm{L}$ & $14.5 \pm 4.7$ & $13 \pm 4$ & $12.7 \pm 3.4$ & $12.6 \pm 3.1$ & 0.004 \\
\hline Hemoglobin, mg/dL & $13.9 \pm 1.3$ & $14.2 \pm 1.3$ & $14.1 \pm 1.1$ & $14.2 \pm 0.9$ & 0.625 \\
\hline Admission glucose, mg/dL & $203 \pm 104$ & $161 \pm 75$ & $147 \pm 64$ & $157 \pm 88$ & $<0.001$ \\
\hline Potassium & $4.4 \pm 0.6$ & $4.1 \pm 0.5$ & $4.1 \pm 0.47$ & $4.05 \pm 0.49$ & $<0.001$ \\
\hline Stent diameter, $\mathrm{mm}$ & $3.1 \pm 0.37$ & $3.13 \pm 0.36$ & $3.15 \pm 0.32$ & $3.06 \pm 0.34$ & 0.277 \\
\hline Stent length, cm & $21.4 \pm 9$ & $19.5 \pm 6.8$ & $18.5 \pm 6.2$ & $20.4 \pm 5.8$ & 0.013 \\
\hline Ejection fraction, $\%$ & $42.2 \pm 12$ & $48.2 \pm 10.2$ & $49.2 \pm 10.1$ & $51.1 \pm 8.8$ & $<0.001$ \\
\hline
\end{tabular}

Variables are reported as mean \pm standard deviation or counts (percentages). F/M: female/male; CAD: coronary artery disease; eGFR: estimated glomerular filtration rate; CK-MB: creatine kinase-myocardial band.

dures were conducted by a highly experienced staff (performing $>75$ PCIs/year), in a high volume center ( $>3,000$ PCIs/ year).

Following the diagnosis of STEMI, the blood samples were obtained from the patients at the emergency department. The eGFR was calculated from these initial blood samples.

Cockroft-Gault $(\mathrm{C}-\mathrm{G})$ equation: $\mathrm{C}-\mathrm{G}=((140$ - age $) \times$ weight $(\mathrm{kg})) /((72 \times$ creatinine $) \times(0.85$ if female $))$ was used for eGFR [16]. Patients were classified into four categories according to the eGFR $(<60,60-<90,90-<120$, and $\geq 120$ $\mathrm{mL} / \mathrm{min} / 1.73 \mathrm{~m}^{2}$ ).

Baseline demographic data were collected from the medical records. The left ventricular EF was measured just before discharge. The modified Simpson's method was used for measurement via a System V (Vingmed, GE, Horten, Norway) [17].

The written informed consent was obtained from all patients and hospital local ethic committee approved the study protocol.

\section{Coronary angiography and primary PCI}

All coronary angiographies and primary PCIs were performed via the femoral approach. The infarct related artery was graded by using thrombolysis in myocardial infarction (TIMI) classification [18]. The coronary artery stenosis was assumed as significant if stenosis was $>50 \%$ of diameter. The primary PCI was applied just to the infarct related artery. Following the diagnosis of STEMI, prior to primary PCI, all patients were loaded with $300 \mathrm{mg}$ clopidogrel and $300 \mathrm{mg}$ aspirin (unless contraindicated). Due to payment strategy of the Minister of Health, ticagrelor and prasugrel were not used. No statin loading was applied before primary PCI. After the revealing of the coronary anatomy, all patients were administered $100 \mathrm{U} / \mathrm{kg}$ heparin. Following the procedure, patients were transferred to the coronary care unit. Intravenous heparin $(500 \mathrm{U} / \mathrm{h})$ or subcutaneous low molecular heparin (enoxaparin) (1 mg/kg/day) was maintained in coronary care unit. Certain medications, e.g. aspirin $100 \mathrm{mg} /$ day, clopidogrel $75 \mathrm{mg} /$ day, rosuvastatin $20 \mathrm{mg}$ /day or atorvastatin $40 \mathrm{mg} /$ day, angiotensin converting enzyme inhibitor or angiotensin receptor blocker, and betablockers were administered according to the hemodynamic status of the patients. Glycoprotein IIb/IIIa receptor blocker (e.g. tirofiban) was used according to the burden of the thrombus on visual assessment.

\section{Definitions}

The Killip clinical examination was used for definition of patient clinical condition at presentation. HT was defined if a patient was on an antihypertensive treatment or requiring an 
Table 2. In-Hospital and Long-Term Events of All Patients by Glomerular Filtration Rate

\begin{tabular}{|c|c|c|c|c|c|}
\hline & \multicolumn{4}{|c|}{ Estimated glomerular filtration rates $\left(\mathrm{mL} / \mathrm{min} / 1.73 \mathrm{~m}^{2}\right)$} & \multirow{2}{*}{$\mathbf{P}$} \\
\hline & $<60$ & $\geq 60-<90$ & $\geq 90-120$ & $\geq 120$ & \\
\hline Shock, n (\%) & $8(11.3)$ & $13(3.4)$ & $4(1.2)$ & - & $<0.001$ \\
\hline Killip class > 1, n (\%) & $19(34.5)$ & $30(11.1)$ & $13(5.1)$ & $3(5.5)$ & $<0.001$ \\
\hline In-hospital mortality, n (\%) & $9(12.5)$ & $5(1.3)$ & $1(0.3)$ & - & $<0.001$ \\
\hline Re-infarction, n (\%) & $3(4.2)$ & $6(1.5)$ & $7(2)$ & $3(3.9)$ & 0.358 \\
\hline TVR, n (\%) & $5(6.9)$ & $19(4.9)$ & $12(3.5)$ & $5(6.5)$ & 0.464 \\
\hline MACE, n (\%) & $12(16.7)$ & $23(5.9)$ & $13(3.8)$ & $5(6.5)$ & 0.001 \\
\hline Stroke, n (\%) & $3(4.2)$ & $3(0.8)$ & $1(0.3)$ & - & 0.007 \\
\hline CPR, n (\%) & $10(13.9)$ & $9(2.3)$ & $5(1.4)$ & - & $<0.001$ \\
\hline Dialysis, n (\%) & $3(4.2)$ & - & - & - & $<0.001$ \\
\hline VT-VF, n (\%) & $9(12.5)$ & $15(3.8)$ & $14(4.1)$ & $3(3.9)$ & 0.012 \\
\hline CHD, n (\%) & $29(40.3)$ & $64(16.4)$ & $43(12.5)$ & $9(11.7)$ & $<0.001$ \\
\hline Inotrop usage, $\mathrm{n}(\%)$ & $19(26.4)$ & $37(9.5)$ & $29(8.4)$ & $2(2.6)$ & $<0.001$ \\
\hline IABP usage, n (\%) & $10(13.9)$ & $15(3.8)$ & $9(2.6)$ & $1(1.3)$ & $<0.001$ \\
\hline Atrial Fibrillation, n (\%) & $6(8.3)$ & $5(1.3)$ & $4(1.2)$ & $1(1.3)$ & $<0.001$ \\
\hline GIS bleeding, $\mathrm{n}(\%)$ & $1(1.4)$ & $2(0.5)$ & $2(0.6)$ & - & 0.723 \\
\hline Inguinal complication, $\mathrm{n}(\%)$ & $3(4.2)$ & $17(4.4)$ & $14(4.1)$ & $1(1.3)$ & 0.656 \\
\hline Thrombus (0 - 1 day), n (\%) & $1(1.4)$ & $1(0.3)$ & $3(0.9)$ & $1(1.3)$ & 0.533 \\
\hline Thrombus (1 - 30 days), n (\%) & $3(4.2)$ & $9(2.3)$ & $7(2)$ & $5(6.5)$ & 0.133 \\
\hline Thrombus (> 30 days), n (\%) & $3(4.2)$ & $8(2.1)$ & $8(2.3)$ & - & 0.369 \\
\hline Transfusion, $\mathrm{n}(\%)$ & $3(4.2)$ & $11(2.8)$ & $4(1.2)$ & $3(3.9)$ & 0.233 \\
\hline Cardiac death on follow-up, n (\%) & $6(9.5)$ & $12(3.1)$ & $11(3.3)$ & $1(1.3)$ & 0.046 \\
\hline CHD/Shock on follow-up, n (\%) & $13(22.8)$ & $38(11.1)$ & $25(8.1)$ & $5(7.4)$ & 0.008 \\
\hline Stroke on follow-up, n (\%) & - & $8(2.4)$ & - & - & 0.017 \\
\hline Re-infarction on follow-up, n (\%) & $10(18.2)$ & $28(8.3)$ & $21(6.8)$ & $9(13.2)$ & 0.026 \\
\hline TVR on follow-up, n (\%) & $18(32.1)$ & $76(22.4)$ & $63(20.3)$ & $17(25)$ & 0.247 \\
\hline MACE on follow-up, n (\%) & $24(41.4)$ & $95(27.5)$ & $71(22.8)$ & $20(29.4)$ & 0.028 \\
\hline
\end{tabular}

Variables are reported as mean \pm standard deviation or counts (percentages). Major adverse cardiac events included mortality, re-infarction and target vessel revascularization. TVR: target vessel revascularization; MACE: major adverse cardiac event; CPR: cardiopulmonary resuscitation; VT-VF: ventricular tachycardia-ventricular fibrillation; CHD: congestive heart disease; IABP: intra-aortic balloon pump; GIS: gastrointestinal system.

antihypertensive drug in hospital. Any patient on an oral antidiabetic drug and/or insulin was assumed to be diabetic. Major adverse cardiac events (MACEs) consisted of cardiovascular mortality, re-infarction and target vessel revascularization (TVR). Re-infarction was defined by ST-segment elevation along with at least two-fold increase in serum creatine kinasemyocardial band (CK-MB) fraction activity.

\section{Statistical analysis}

All quantitative variables were expressed as mean \pm standard deviation (SD), and qualitative variables were expressed as percent (\%). Comparison of parametric values between four groups was performed using the one-way ANOVA test. Nonparametric values between four groups were analyzed using the Mann-Whitney U test. Categorical variables were compared by the Chi-square test or Fisher's exact test. Stepwise, multivariate Cox regression analysis, which included variables with a $P$ value of less than 0.1 , was performed to identify independent predictors. Age, gender, history, duration of hospitalization, left ventricular EF, volume, CK-MB, potassium, percent of stenosis, diameter and length of the stent, HT, and admission $\mathrm{Cr}$ were included in the model. A two-sided $\mathrm{P}$ value of less than 0.05 was considered statistically significant. All statistical studies were carried out with SPSS program (version 15.0, SPSS, Chicago, IL, USA).

\section{Results}

A total of 884 patients (113 female) undergoing primary PCI 
Table 3. Logistic Regression Models for In-Hospital Mortality by Estimated Glomerular Filtration Rate

\begin{tabular}{|c|c|c|c|c|}
\hline \multirow{2}{*}{ Mortality } & \multicolumn{4}{|c|}{ Estimated glomerular filtration rates $\left(\mathrm{mL} / \mathrm{min} / 1.73 \mathrm{~m}^{2}\right)$} \\
\hline & $<60$ & $\geq 60-<90$ & $\geq 90-120$ & $\geq 120$ \\
\hline Model 1 & $7.78(0.91-66.8)$ & $2.41(0.31-18.7)$ & $2.49(0.32-19.6)$ & 1 (Reference) \\
\hline Model 2 & $4.57(0.5-41.1)$ & $1.74(0.21-13.9)$ & $2.37(0.29-18.7)$ & 1 (Reference) \\
\hline Model 3 & $4.3(0.46-39.6)$ & $1.81(0.22-14.5)$ & $2.49(0.31-19.8)$ & 1 (Reference) \\
\hline Model 4 & $2.92(0.23-36.8)$ & $1.16(0.12-10.8)$ & $1.37(0.14-12.7)$ & 1 (Reference) \\
\hline
\end{tabular}

All data are presented as odds ratio (95\% confidence interval). Logistic models: model 1: unadjusted model; model 2: adjusted model for age and sex; model 3: adjusted model for age, sex and past medical history; model 4: adjusted model for all covariates including age, gender, history, duration of hospitalization, left ventricular ejection fraction, CK-MB, potassium, diameter and length of the stent.

were enrolled to the study. Patients with renal dysfunction were often more female and older $(\mathrm{P}<0.001$ and $\mathrm{P}<0.001)$ (Table 1). Even though patients with eGFR $<60 \mathrm{~mL} / \mathrm{min} / 1.73$ $\mathrm{m}^{2}$ were more diabetic and hypertensive, this did not reach statistical significance $(\mathrm{P}=0.137$ and $\mathrm{P}=0.072)$. The history of coronary artery disease and smoking did not differ between groups. With respect to laboratory findings, leucocyte count, CK-MB, admission glucose, and potassium levels were higher in the eGFR $<60 \mathrm{~mL} / \mathrm{min} / 1.73 \mathrm{~m}^{2}$ group $(\mathrm{P}=0.004, \mathrm{P}<0.001$, $\mathrm{P}<0.001$, and $\mathrm{P}<0.001$, respectively). The left ventricular EF significantly differed between groups $(\mathrm{P}<0.001)$. Patients with eGFR $<60 \mathrm{~mL} / \mathrm{min} / 1.73 \mathrm{~m}^{2}$ group hospitalized longer $(\mathrm{P}$ $=0.004)$.

In-hospital complications, including shock, ventricular arrhythmias, inotropic usage, atrial fibrillation, and intra-aortic balloon pump (IABP) usage were significantly different between groups $(\mathrm{P}<0.001, \mathrm{P}=0.012, \mathrm{P}<0.001, \mathrm{P}<0.001$, and $\mathrm{P}<0.001$, respectively) (Table 2 ). In-hospital MACE majorly driven by in-hospital mortality was significantly higher in eGFR $<60 \mathrm{~mL} / \mathrm{min} / 1.73 \mathrm{~m}^{2}$ group $(\mathrm{P}<0.001$ and $\mathrm{P}<0.001$, respectively). Even though the number was small, in-hospital stroke occurred more frequently in eGFR $<60 \mathrm{~mL} / \mathrm{min} / 1.73$ $\mathrm{m}^{2}$ group $(\mathrm{P}=0.07)$. Short- and long-term stent thrombosis and TVR were similar between groups $(\mathrm{P}=0.133, \mathrm{P}=0.369, \mathrm{P}$ $=0.464$, and $\mathrm{P}=0.247$, respectively). Long-term MACE was higher in eGFR $<60 \mathrm{~mL} / \mathrm{min} / 1.73 \mathrm{~m}^{2}$ group and was driven by mortality and re-infarction $(\mathrm{P}=0.028, \mathrm{P}=0.046$, and $\mathrm{P}=$ 0.026 , respectively).

The unadjusted and adjusted models of logistic regression analysis for mortality according to eGFR are listed in Table 3. The mortality had the highest rates at eGFR $<60 \mathrm{~mL} / \mathrm{min} / 1.73$ $\mathrm{m}^{2}$ level and had 7.78 times higher mortality rates $(95 \% \mathrm{CI}$ : 0.91 - 66.8) than eGFR $>120 \mathrm{~mL} / \mathrm{min} / 1.73 \mathrm{~m}^{2}$, which had the lowest rates as reference. After adjusted regression analysis, eGFR $<60 \mathrm{~mL} / \mathrm{min} / 1.73 \mathrm{~m}^{2}$ still had a 2.92 times higher mortality rate (95\% CI: 0.23 - 36.8).

\section{Discussion}

The present study demonstrated that any degree of renal impairment is associated with increased in-hospital and longterm mortality and MACE in patients presenting with STEMI undergoing primary PCI. Also, patients with renal impairment had lower left ventricular EF and higher cardiac enzyme. On the other hand, no relation was found between stent thrombosis and renal impairment for short- and long-term period.

Serum Cr level solely did not predict the severity of renal function. Even serum $\mathrm{Cr}$ level could stay in normal range until moderate and severe renal impairment developed $[2,7]$. That is why eGFR was used for prediction of renal dysfunction. Generally, modification of diet in renal disease (MDRD) formula was used for prediction of eGFR in previous studies and in clinical practice $[2,7]$. In our previous study, we found that C-G derived eGFR predicts worse prognosis better than MDRD in STEMI [19]. This was a major difference between present and previous studies.

It was demonstrated that renal impairment is more frequently associated with HT and DM in addition to older age and female gender [7]. These clinical factors are associated with poor prognosis in acute MI [7]. Even though in the present study patients with renal impairment are mostly female, older and more frequently had HT and DM, after multivariate regression analysis, eGFR derived renal impairment is still prognostic in STEMI patients undergoing primary PCI.

The relation between CKD and cardiovascular mortality is well known [1-3]. Several different studies have shown that even mild degree of renal impairment is related with increased adverse outcomes in normal population and patients with cardiac disease. A similarly designed study with the present one shows that an eGFR $<30 \mathrm{~mL} / \mathrm{min} / 1.73 \mathrm{~m}^{2}$ is associated with increased in-hospital and 1-year mortality [20]. In the present study, we show that long-term mortality and adverse events are sustained beyond 2 years. And also regression analysis showed that mild degree of renal impairment is related with adverse events. There are some potential explanations why renal impairment is associated with worse outcomes. Firstly, it has shown that as eGFR decreased, fibroblast and parathyroid hormone levels increased. As a result, vitamin D and phosphate metabolisms are deteriorated which leads to vascular dysfunction and coronary artery disease $[6,21,22]$. Secondly, potential explanation is that renal impairment is associated with enhanced pro-coagulant state, increased homocysteine levels, and endothelial dysfunction that eventually lead to atherosclerotic plaque formation and destabilization [2, 23]. A recent study by Duran et al showed that mild and moderate renal impairment is associated with increased atherosclerosis burden [13]. 
Another important finding of our study was that as left ventricular EF decreased, eGFR also decreased. Also, CK-MB level was highest in the eGFR $<60 \mathrm{~mL} / \mathrm{min} / 1.73 \mathrm{~m}^{2}$ group. In a recent study, Sonmez et al found that in patients with STEMI undergoing primary PCI, an eGFR $<60 \mathrm{~mL} / \mathrm{min} / 1.73 \mathrm{~m}^{2}$ is associated with lower left ventricular EF and larger myocardial infarct size [12].

Some other findings of the present study were in accordance with the previous studies. The hospitalization duration was longer in lowest eGFR group as in Alfaleh et al's study, probably as a result of increased in-hospital adverse events [24]. Previous reports indicated that the risk of stroke increases with renal impairment [24, 25]. Even though the number of stroke was low, in the present study, there was a significant inverse relation with eGFR and stroke.

In the present study, the rate of stent thrombosis did not differ significantly between groups. There are different results in previous studies in regard of different types of stents. In a study performed by Miao et al, CKD, in elective DES implantation patients, was associated with increased stent thrombosis [26]. Another study that excluded STEMI patients showed that in patients with eGFR $<60 \mathrm{~mL} / \mathrm{min} / 1.73 \mathrm{~m}^{2}$, DES usage is not associated with stent thrombosis but reduced myocardial infarction and rate of repeat revascularization [27]. Similar to Wang et al's study, Toutouzas et al showed that new generation DES did not increase the rate of stent thrombosis in CKD patients [28]. Another study performed with bare metal stents showed an inverse relation between renal dysfunction and neointima formation after BMS deployment. In that study the neointima intravascular ultrasound showed greater lipid volume, suggesting atherosclerosis development [29]. In the present study, BMS was deployed for stent implantation. For BMS, restenosis rather than thrombosis is a concern [30]. Probably this could be the explanation why no difference of stent thrombosis was found between groups.

The present study had several limitations. Firstly, this study was retrospective and single-centered. Secondly, just the effect of admission $\mathrm{Cr}$ derived eGFR was used for assessment. Thirdly, the impact of in-hospital medication on prognosis and eGFR was not assessed. Fourthly, the standard method of renal function assessment, $24 \mathrm{~h} \mathrm{Cr}$ clearance, was not performed.

\section{Conclusions}

In conclusion, the present study demonstrated that any degree of renal impairment and especially eGFR $<60 \mathrm{~mL} / \mathrm{min} / 1.73$ $\mathrm{m}^{2}$ was associated with increased in-hospital and long-term mortality and MACE and decreased left ventricular EF. C-G derived eGFR is a simple, easily bedside applicable method of renal impairment for risk stratification in STEMI patients undergoing primary PCI.

\section{Conflict of Interest}

The authors declare no conflicts of interest with respect to the research, authorship, and/or publication of this article.

\section{References}

1. Akkaya E, Ayhan E, Uyarel H, Ergelen M, Turer A, Demirci D, Cicek G, et al. [The impact of chronic kidney disease on in-hospital clinical outcomes in patients undergoing primary percutaneous angioplasty for ST-segment elevation myocardial infarction]. Turk Kardiyol Dern Ars. 2011;39(4):276-282.

2. Anavekar NS, McMurray JJ, Velazquez EJ, Solomon SD, Kober L, Rouleau JL, White HD, et al. Relation between renal dysfunction and cardiovascular outcomes after myocardial infarction. N Engl J Med. 2004;351(13):12851295.

3. Matsushita K, van der Velde M, Astor BC, Woodward M, Levey AS, de Jong PE, Coresh J, et al. Association of estimated glomerular filtration rate and albuminuria with all-cause and cardiovascular mortality in general population cohorts: a collaborative meta-analysis. Lancet. 2010;375(9731):2073-2081.

4. Blasco L, Sanjuan R, Carbonell N, Solis MA, Puchades MJ, Torregrosa I, Miguel JA. Estimated Glomerular Filtration Rate in Short-Risk Stratification in Acute Myocardial Infarction. Cardiorenal Med. 2011;1(2):131-138.

5. Campbell NG, Varagunam M, Sawhney V, Ahuja KR, Salahuddin N, De Palma R, Rothman MT, et al. Mild chronic kidney disease is an independent predictor of long-term mortality after emergency angiography and primary percutaneous intervention in patients with ST-elevation myocardial infarction. Heart. 2012;98(1):42-47.

6. Oh SW, Baek SH, Kim YC, Goo HS, Heo NJ, Na KY, Chae DW, et al. Mild decrease in estimated glomerular filtration rate and proteinuria are associated with all-cause and cardiovascular mortality in the general population. Nephrol Dial Transplant. 2012;27(6):2284-2290.

7. Kim JY, Jeong MH, Ahn YK, Moon JH, Chae SC, Hur SH, Hong TJ, et al. Decreased Glomerular Filtration Rate is an Independent Predictor of In-Hospital Mortality in Patients With ST-Segment Elevation Myocardial Infarction Undergoing Primary Percutaneous Coronary Intervention. Korean Circ J. 2011;41(4):184-190.

8. Donfrancesco C, Palleschi S, Palmieri L, Rossi B, Lo Noce C, Pannozzo F, Spoto B, et al. Estimated glomerular filtration rate, all-cause mortality and cardiovascular diseases incidence in a low risk population: the MATISS study. PLoS One. 2013;8(10):e78475.

9. Damman P, Kikkert WJ, Woudstra P, Kuijt WJ, Grundeken MJ, Harskamp RE, Baan J, et al. Gender difference in the prognostic value of estimated glomerular filtration rate at admission in ST-segment elevation myocardial infarction: a prospective cohort study. BMJ Open. 2012;2(2): $\mathrm{e} 000322$.

10. Celik T, Iyisoy A, Yuksel CU, Kilic S, Yilmaz MI, Akgul EO, Jata B, et al. Impact of admission glomerular filtration rate on the development of poor myocardial perfusion after primary percutaneous intervention in patients with acute myocardial infarction. Coron Artery Dis. 2008;19(8):543-549.

11. Kurtul A, Murat SN, Yarlioglues M, Duran M, Celik IE, 
Kilic A. Mild to Moderate Renal Impairment Is Associated With No-Reflow Phenomenon After Primary Percutaneous Coronary Intervention in Acute Myocardial Infarction. Angiology. 2015;66(7):644-651.

12. Sonmez O, Vatankulu MA, Tasal A, Bacaksiz A, Ayhan S, Yazici HU, Karakaya E, et al. Does estimated glomerular filtration rate have an effect on left ventricular function after ST-elevation myocardial infarction? Echocardiography. 2014;31(3):318-324.

13. Duran M, Uysal OK, Gunebakmaz O, Baran O, Turfan M, Ornek E, Cetin M, et al. Glomerular filtration rate is associated with burden of coronary atherosclerosis in patients with acute coronary syndrome. Angiology. 2014;65(4):350-356.

14. Thygesen K, Alpert JS, Jaffe AS, Simoons ML, Chaitman BR, White HD, Katus HA, et al. Third universal definition of myocardial infarction. Eur Heart J. 2012;33(20):25512567.

15. Colaco R, Reay P, Beckett C, Aitchison TC, McFarlane PW. False positive ECG reports of anterior myocardial infarction in women. J Electrocardiol. 2000;33(Suppl):239-244.

16. Cockcroft DW, Gault MH. Prediction of creatinine clearance from serum creatinine. Nephron. 1976;16(1):31-41.

17. Schiller NB, Shah PM, Crawford M, DeMaria A, Devereux R, Feigenbaum $\mathrm{H}$, Gutgesell $\mathrm{H}$, et al. Recommendations for quantitation of the left ventricle by two-dimensional echocardiography. American Society of Echocardiography Committee on Standards, Subcommittee on Quantitation of Two-Dimensional Echocardiograms. J Am Soc Echocardiogr. 1989;2(5):358-367.

18. Chesebro JH, Knatterud G, Roberts R, Borer J, Cohen LS, Dalen J, Dodge HT, et al. Thrombolysis in Myocardial Infarction (TIMI) Trial, Phase I: A comparison between intravenous tissue plasminogen activator and intravenous streptokinase. Clinical findings through hospital discharge. Circulation. 1987;76(1):142-154.

19. Ekmekci A, Uluganyan M, Gungor B, Tufan F, Cekirdekci EI, Ozcan KS, Erer HB, et al. Comparison of CockcroftGault and modification of diet in renal disease formulas as predictors of cardiovascular outcomes in patients with myocardial infarction treated with primary percutaneous coronary intervention. Angiology. 2014;65(9):838-843.

20. Tsai TH, Yeh KH, Sun CK, Yang CH, Chen SM, Hang CL, Chen CJ, et al. Estimated glomerular filtration rate as a useful predictor of mortality in patients with acute myocardial infarction undergoing primary percutaneous coronary intervention. Am J Med Sci. 2013;345(2):104111.

21. Yilmaz MI, Sonmez A, Saglam M, Yaman H, Kilic S, Demirkaya E, Eyileten T, et al. FGF-23 and vascular dysfunction in patients with stage 3 and 4 chronic kidney disease. Kidney Int. 2010;78(7):679-685.

22. Naito K, Anzai T, Yoshikawa T, Anzai A, Kaneko H, Kohno $\mathrm{T}$, Takahashi $\mathrm{T}$, et al. Impact of chronic kidney disease on postinfarction inflammation, oxidative stress, and left ventricular remodeling. J Card Fail. 2008;14(10):831-838.

23. Shlipak MG, Fried LF, Crump C, Bleyer AJ, Manolio TA, Tracy RP, Furberg CD, et al. Elevations of inflammatory and procoagulant biomarkers in elderly persons with renal insufficiency. Circulation. 2003;107(1):87-92.

24. AlFaleh HF, Alsuwaida AO, Ullah A, Hersi A, AlHabib KF, AlShahrani A, AlNemer K, et al. Glomerular filtration rate estimated by the CKD-EPI formula is a powerful predictor of in-hospital adverse clinical outcomes after an acute coronary syndrome. Angiology. 2012;63(2):119126.

25. Wannamethee SG, Shaper AG, Perry IJ. Serum creatinine concentration and risk of cardiovascular disease: a possible marker for increased risk of stroke. Stroke. 1997;28(3):557-563.

26. Miao Y, Yu-Jie Z, Zhi-Jian W, Dong-Mei S, Yu-Yang L, Ying-Xin Z, Fei G, et al. Chronic kidney disease and the risk of stent thrombosis after percutaneous coronary intervention with drug-eluting stents. Catheter Cardiovasc Interv. 2012;80(3):361-367.

27. Wang ZJ, Harjai KJ, Shenoy C, Gao F, Shi DM, Liu YY, Zhao YX, et al. Drug-eluting stents versus bare-metal stents in patients with decreased GFR: a meta-analysis. Am J Kidney Dis. 2013;62(4):711-721.

28. Toutouzas K, Patsa C, Synetos A, Karanasos A, Karampelas J, Tsiamis E, Spanos A, et al. The impact of new generation drug-eluting stent implantation on patients with chronic kidney disease and a single lesion in the proximal segment of the left anterior descending artery. Hellenic J Cardiol. 2011;52(2):103-110.

29. Hayano S, Ishii H, Ichimiya S, Kanashiro M, Watanabe J, Suzuki S, Yoshikawa D, et al. Renal dysfunction and atherosclerosis of the neointima following bare metal stent implantation. Am J Nephrol. 2013;38(1):58-65.

30. Yoshida T, Sakata K, Nitta Y, Taguchi T, Kaku B, Katsuda $\mathrm{S}$, Shimojima M, et al. Short- and long-term benefits of drug-eluting stents compared to bare metal stents even in treatment for large coronary arteries. Heart Vessels. 2015. 